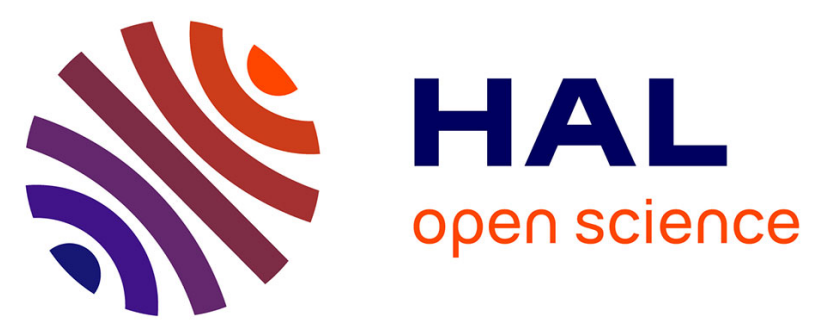

\title{
Activation of olefin metathesis complexes containing unsymmetrical unsaturated N-heterocyclic carbenes by copper and gold transmetalation
}

Fadwa Kamal, Sophie Colombel-Rouen, Adrien Dumas, Jean-Paul Guégan, Thierry Roisnel, Vincent Dorcet, Olivier Baslé, Mathieu Rouen, Marc Mauduit

\section{To cite this version:}

Fadwa Kamal, Sophie Colombel-Rouen, Adrien Dumas, Jean-Paul Guégan, Thierry Roisnel, et al.. Activation of olefin metathesis complexes containing unsymmetrical unsaturated N-heterocyclic carbenes by copper and gold transmetalation. Chemical Communications, 2019, 55 (77), pp.11583-11586. $10.1039 / \mathrm{c} 9 \mathrm{cc} 05776 \mathrm{e}$. hal-02307034

\section{HAL Id: hal-02307034}

\section{https://hal-univ-rennes1.archives-ouvertes.fr/hal-02307034}

Submitted on 4 Dec 2019

HAL is a multi-disciplinary open access archive for the deposit and dissemination of scientific research documents, whether they are published or not. The documents may come from teaching and research institutions in France or abroad, or from public or private research centers.
L'archive ouverte pluridisciplinaire HAL, est destinée au dépôt et à la diffusion de documents scientifiques de niveau recherche, publiés ou non, émanant des établissements d'enseignement et de recherche français ou étrangers, des laboratoires publics ou privés. 


\section{Activation of olefin metathesis complexes containing unsymmetrical unsaturated $\mathrm{N}$-heterocyclic carbenes by copper and gold transmetalation}

Received 00th January 20xx, Accepted 00th January 20xx

DOI: $10.1039 / \mathrm{x} 0 \mathrm{xx} 00000 \mathrm{x}$

www.rsc.org/

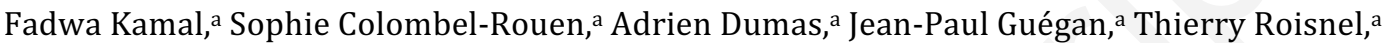
Vincent Dorcet, ${ }^{\mathrm{a}}$ Olivier Baslé, ${ }^{\mathrm{a}}+$ Mathieu Rouen ${ }^{\mathrm{b}}$ and Marc Mauduit*a
The activation of ruthenium-indenylidene complexes containing two unsymmetrical unsaturated $\mathrm{N}$-heterocyclic carbenes (u2NHCs) by a transmetalation process is reported. The use of copper(I) or gold(I) chlorides promotes the rapid trapping of one NHC ligand that releases the catalytic active Ru-species. Impressive initiation rates with full-conversions are observed within one minute. This practical protocol demonstrates excellent catalytic performances in various ring-closing metathesis (RCM) and self-metathesis (SM).

In a few decades, olefin metathesis has rapidly become one of the most efficient synthetic tools in organic chemistry This attractiveness was mainly due to the development of efficient, well-defined, air stable and easy to handle rutheniumarylidene complexes with high tolerance towards many organic functions. ${ }^{1}$ Since the pioneer works describing the phosphine-based Grubbs first-generation catalyst in early $1990 \mathrm{~s}^{2}$ the research efforts to furnish more robust and powerful complexes have drastically increased. ${ }^{1,3}$ The development of catalysts containing a $\mathrm{N}$-Heterocyclic Carbene (NHC) ligand that demonstrated higher stability and activity, known as Grubbs second generation catalysts, represents certainly the most successful achievement in this field. ${ }^{4}$ While numerous catalysts bearing one NHC unit have been intensively developed, ${ }^{5}$ the class of Ru-complexes featuring two NHCs has scarcely been investigated. Historically, the first members of this class were reported in 1998 by the Herrmann group prior to the Grubbs second generation catalyst. ${ }^{6}$ Unfortunately, due to a stronger coordination of the NHC ligand, a significant thermal stimulus was needed to observe satisfactory activities in olefin metathesis. In recent years, a renewed interest has taken place for these catalysts, notably in materials science, in which a full-control of the catalytic initiation of the metathesis polymerisation is strongly

\footnotetext{
a. Univ Rennes, Ecole Nationale Supérieure de Chimie de Rennes, CNRS, ISCR - UMR 6226, F-35000 Rennes, France.

b. DEMETA SAS, 6 rue Pierre-Joseph Colin, 35000 Rennes, France.

E-mail: marc.mauduit@ensc-rennes.fr

† Present address: LCC-CNRS, Université de Toulouse, CNRS, UPS, Toulouse, France $\dagger$ Electronic Supplementary Information (ESI) available: Experimental procedures, NMR spectra. CCDC 1937862, 1937863, 1938684 and 1938686. For ESI and crystallographic data see DOI: 10.1039/x0xx00000x
}

required. ${ }^{7}$ Several strategies were reported to improve their catalytic performances by facilitating the decoordination of one NHC ligand with noteworthy successes. ${ }^{8}$ Notably, the introduction of electron-deficient $\mathrm{NHC}$ ligands ${ }^{9}$ or small $\mathrm{NHC}$ units $^{10}$ could enhance the activity of the related complexes with catalyst loadings as low as 0.05 mol\% (Figure 1, a). In 2011, Grubbs and Bertrand successfully reported the use of a Brønsted acid as external stimulus to promote the protonolysis of a mesoionic carbene (MIC). ${ }^{11}$ The resulting $14 \mathrm{e}$ - catalytic species proved to be extremely active, surpassing current commercial Ru-catalysts (Figure 1, b-left). More recently, our group synthesised new complexes Ru-1 containing two unsymmetrical unsaturated $\mathrm{N}$-cycloalkyl-NHCs (u2NHCs) that were activated by anhydrous $\mathrm{HCl}$ (Figure 1, b-right). ${ }^{12}$ These catalysts were quite efficient in various metathesis transformations, notably in macrocyclic ring-closing metathesis (RCM) yielding various macrocyclic odorant molecules of remarkable $>99 \%$ purity. Nevertheless, the use of anhydrous $\mathrm{HCl}$ remained difficult to handle. ${ }^{13}$

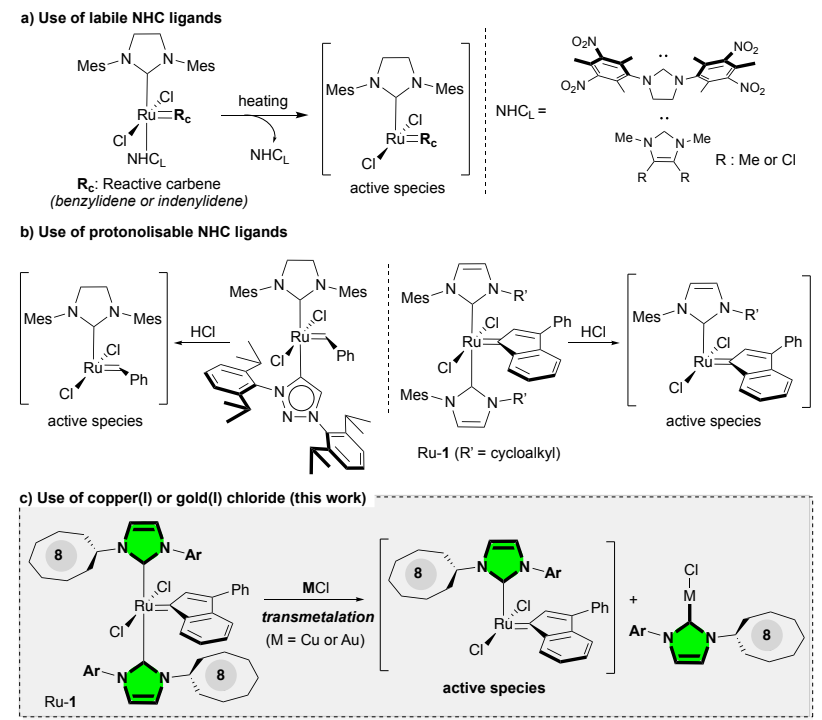

Fig. 1 Previously reported activation of Ru-complexes containing two NHC ligands (a and b) and the proposed transmetalation protocol (c, this work) 
We would like now to report an efficient activation of Ruindenylidene complexes Ru-1 containing two u2-NHCs by a transmetalation process involving copper(I) or gold(I) chlorides. The rapid release of the active catalytic Ru-species in the reaction media led to impressive initiation rates with full conversions that occur within a few minutes. Through this practical protocol, excellent catalytic performances were observed in various RCM and SM.

In 1997, Grubbs and co-workers were the first to report the beneficial use of copper(I) chloride to enhance the initiation rates of well-defined $\left(\mathrm{PR}_{3}\right)_{2} \mathrm{X}_{2} \mathrm{Ru}=\mathrm{CH}-\mathrm{CH}=\mathrm{Ph}_{2}$ precatalysts during RCM transformations. ${ }^{14 a}$ Albeit the nature of the resulting species was unknown, the authors suspected that $\mathrm{CuCl}$ could act as a phosphine scavenger. Later, Blechert and co-workers used this protocol to enhance the turnover number (TON) of Grubbs $2^{\text {nd }}$ generation precatalyst in crossmetathesis of reluctant acrylonitrile. ${ }^{14 b}$ It is worth to underline that the phosphine-scavenging effect was also successfully employed to improve the synthesis of phosphine-free styrenylether Ru-catalysts (i.e. Hoveyda type precatalyst). ${ }^{15}$ More recently, Thuo and co-workers reported that copper(I) halides limited drastically the formation of isomerized byproduct when metathesis reaction occurred in polar protic solvents with phosphine-based Grubbs catalysts. ${ }^{16}$ Based on these reports, we decided to examine the ability of copper(I) or gold(I) salts to activate our bis-u2NHC Ru-1 by sequestering one NHC ligand (Figure 1, c). First, the transmetalation process was investigated by reacting Ru-1a complex with stoichiometric amounts of $\mathrm{CuCl}$ and 1-isopropoxy-2vinylbenzene $\mathbf{L} 1$ in $\mathrm{CH}_{2} \mathrm{Cl}_{2}$ at $50{ }^{\circ} \mathrm{C}$ (Scheme 1). We were delighted to observe remarkable conversions for expected Hoveyda-type catalyst Ru-2a and copper-u2NHC Cu-1a after 5 $\mathrm{h}$ of reaction (>95\%, see ESI for details).

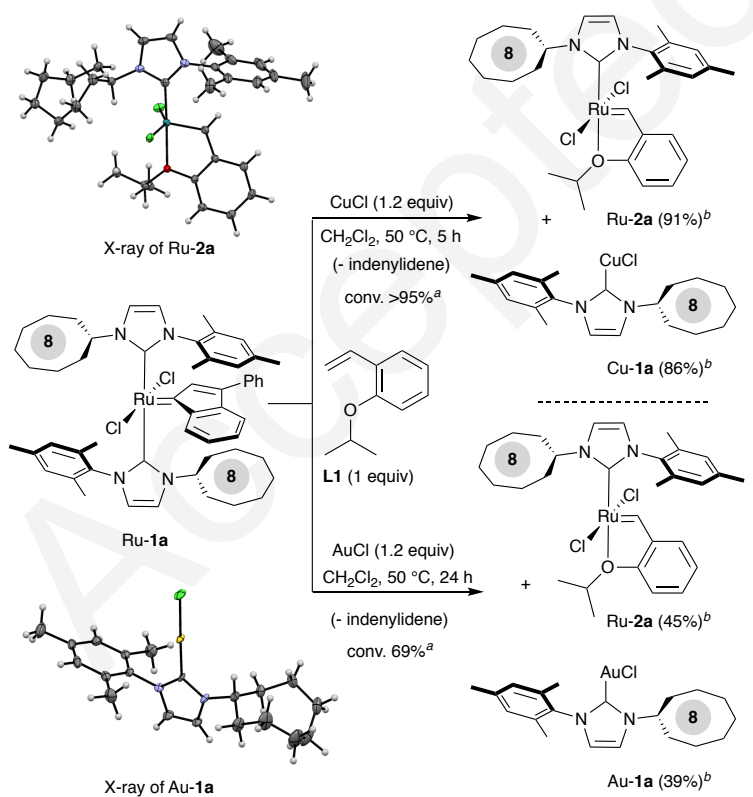

Scheme 1 Transmetalation process involving $\mathrm{Cu}(\mathrm{I})$ and $\mathrm{Au}(\mathrm{I})$ salts with bis-u2NHC Ru-1a complex. ${ }^{a}$ Determined by ${ }^{1} \mathrm{H}$ NMR spectroscopy with 1,3,5-trimethoxybenzene as internal standard. ${ }^{b}$ Isolated yield
Moreover, thanks to their robustness toward silica gel, Ru-2a and $\mathrm{Cu}-1 \mathrm{a}$ were isolated in excellent 91 and $86 \%$ yields after purification. Interestingly, the transmetalation process also succeed with gold(I) chloride but required higher reaction time (24 h) to reach $69 \%$ conversion. Ru-2a and gold-u2NHC Au-1a were isolated in respectively 45 and $39 \%$ yield after purification. Additionally, X-ray diffraction analysis unambiguously confirmed the structure of Ru-2a and Au-1a (Scheme 1). Unfortunately, all attempts to isolate suitable single crystals of $\mathrm{Cu}-1 \mathrm{a}$ remained unsuccessful.

With this efficient protocol of activation in hands, the catalytic activity profile of Ru-1a was studied for the RCM of diethyldiallylmalonate (DEDAM) S1 under standard conditions (1 mol\%, $0.1 \mathrm{M}) .{ }^{17 a}$ As depicted in figure 2 , the critical role of $\mathrm{CuCl}$ and $\mathrm{AuCl}$ appeared quite prominent. At $30{ }^{\circ} \mathrm{C}$, as expected for a bis-NHC catalyst, Ru-1a showed a very slow reactivity toward diene $\mathbf{S 1}$ with only $10 \%$ conv. after two hours ( $67 \%$ at $24 \mathrm{~h}$, Fig. S5, ESI). Addition of $\mathrm{CuCl}$ ( $5 \mathrm{~mol} \%$ ) led to a fast initiation of the metathesis reaction, reaching up to $80 \%$ conv. after only $20 \mathrm{~min}$. and a full conversion after $40 \mathrm{~min} .{ }^{17 \mathrm{~b}}$ With gold activator, an impressive initiation rate occurred converting up to $80 \%$ of S1 within 5 min., however the catalytic system became rapidly less productive as a very slow consumption was observed after 2 hours ( $84 \%$ conv.).
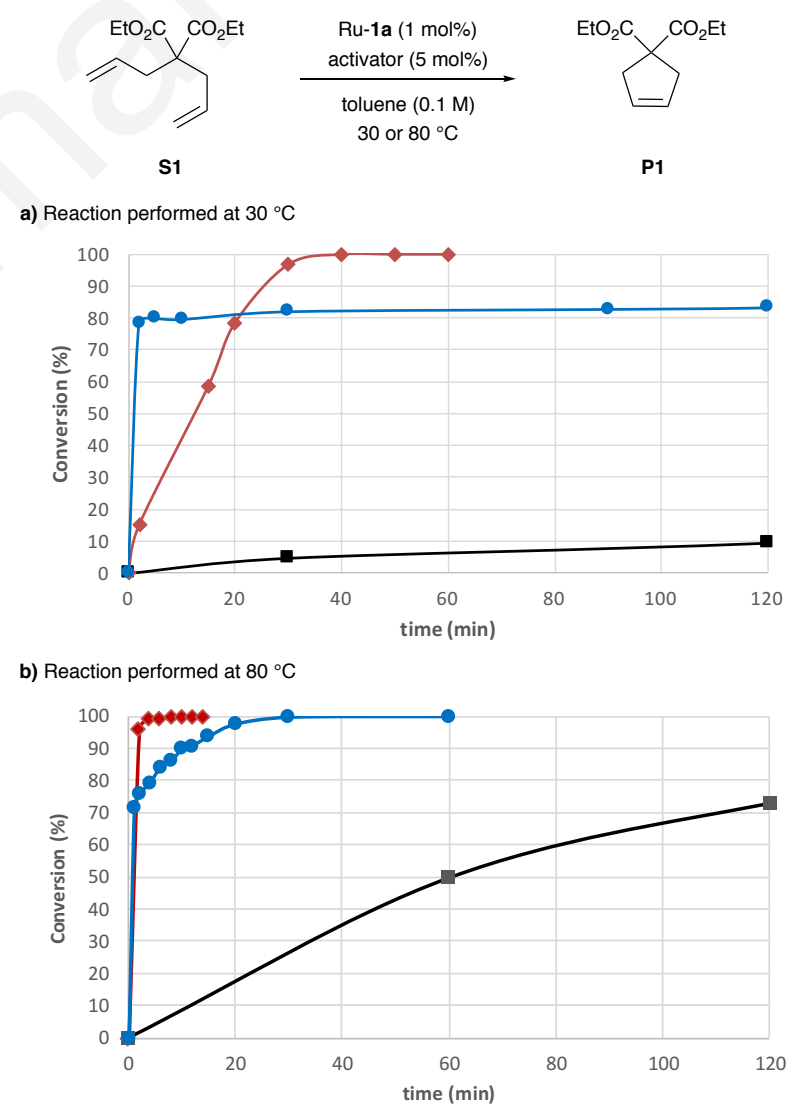

Fig. 2 Catalytic activity profile of Ru-1a catalyst for RCM of DEDAM $\mathbf{S 1}$ at $30{ }^{\circ} \mathrm{C}$ (a) and $80{ }^{\circ} \mathrm{C}$ (b) without (black line) or with activators: $\mathrm{CuCl}$ (red line); $\mathrm{AuCl}$ (blue line). Conversions were monitored by ${ }^{1} \mathrm{H}$ NMR spectroscopy with 1,3,5-trimethoxybenzene as internal standard. 
At $80{ }^{\circ} \mathrm{C}$, while Ru-1a became productive reaching $73 \%$ conv. over 2 hours (and $>99 \%$ after 6 h, Fig. S7, ESI), the copperactivation drastically enhanced the reaction rate with a full conversion within 4 minutes. Remarkably, a similar trend also occurred with only $0.1 \mathrm{~mol} \%$ of catalyst loading (and $0.5 \mathrm{~mol} \%$ of $\mathrm{CuCl}$ ) as $>99 \%$ conv. were reached after $30 \mathrm{~min}$. (see Fig. S6, $\mathrm{ESI}$ ). Regarding $\mathrm{AuCl}$, the catalytic activation was also impressive with a full consumption of $\mathbf{S 1}$ after $30 \mathrm{~min}$. Encouraged by this, the transmetalation activation for other bis-NHC Ru-complexes was next investigated. To this end, we synthesized Ru-1b, Ru-1c and Ru-1d complexes (Figure 3). Precatalyst Ru-1b containing mixed NHCs, i.e. one SIMes and one cyclooctylıMes ligands, was isolated in 55\% yield from commercially available $\mathbf{M} 2$ (see Scheme S1, ESI). Furthermore, complexes Ru-1c and Ru-1d containing two u2NHC featuring halogeno- $N$-aryl substituents were synthesized in good yields following our protocol developed for Ru-1a (57\%, see Scheme S2, ESI). Moreover, the structure of complex Ru-1b was confirmed by single crystal X-ray diffraction studies (Figure 3 ).
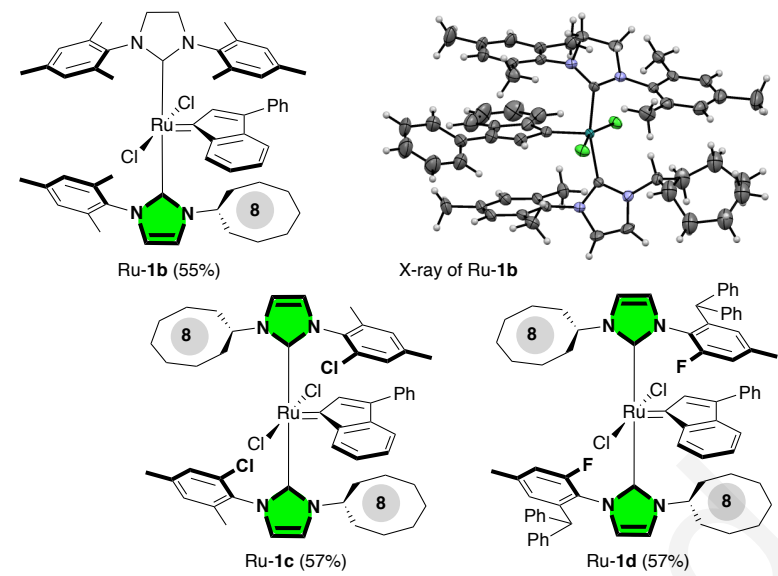

Fig. 3 Newly synthetized bis-NHC containing Ru-complexes $\mathbf{1 b}, \mathbf{1 c}$ and $\mathbf{1 d}$ and solidstate structure of Ru-1b from single crystal $\mathrm{X}$-ray diffraction ( $\mathrm{N}$ in blue, $\mathrm{C}$ in grey, $\mathrm{Cl}$ in green and Ru in pink).

The catalytic profile of Ru-1b-d towards the benchmark RCM was then examined (Table 1). First, the transmetalation with copper or gold drastically doped the catalytic activity of Ru-1b by completing the metathesis within $5 \mathrm{~min}$. at $80^{\circ} \mathrm{C}$ (entries 2 and 4). Again, at $30{ }^{\circ} \mathrm{C}$, the copper activation was more pronounced with a full conversion occurring over $20 \mathrm{~min}$. while only $68 \%$ were reached in presence of $\mathrm{AuCl}$ (entries 1 and 3). Interestingly, Ru-1c and Ru-1d surpassed their Ru-1a-b congeners with full conversions within a few minutes in presence of $\mathrm{CuCl}$, whatever the temperature of the reaction (entries 5-6 and 9-10). With $\mathrm{AuCl}$, similar trends were observed at $80{ }^{\circ} \mathrm{C}$ (entries 8 and 12 ) but at $30^{\circ} \mathrm{C}$, despite a rapid initiation rate $(70 \%$ for $\mathrm{Ru}-1 \mathrm{c}$ and $86 \%$ for Ru-1d, entries 7 and $11)$, catalytic systems became rapidly less productive with a slower evolution of the metathesis. To illustrate this new and efficient activation protocol towards u2-NHC Ru-precatalysts, we turned our attention to other valuable olefin metathesis reactions (Scheme 2). Depending of the targeted transformation, $\mathrm{CuCl}$ or $\mathrm{AuCl}$ were chosen. To our delight, moderate to excellent yields were observed in short times (10 to $30 \mathrm{~min}$.) for RCM, excepted for reluctant substrate $\mathbf{P} 11^{18}$ that remained totally inert, even at $120^{\circ} \mathrm{C}$. Regarding the selfmetathesis of terminal olefins performed in neat condition at $60{ }^{\circ} \mathrm{C}, \mathrm{CuCl}$ was inappropriate as many isomerized by-products and related secondary metathesis products were also produced (see Fig. S15 and S16, ESI).

Table 1 Catalytic activity of Ru-1b,-1c,-1d catalysts in RCM of DEDAM S1 with activator ${ }^{a}$

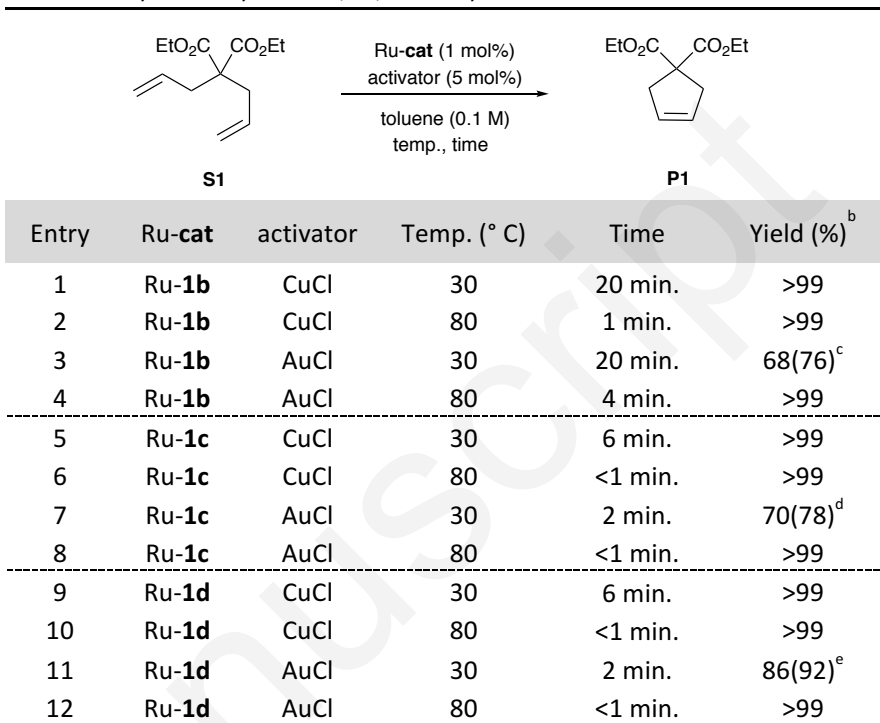

${ }^{a}$ Reaction conditions: DEDAM S1 (1 mmol), catalyst $(0.01 \mathrm{mmol})$, activator $(0.05 \mathrm{mmol})$, toluene (1 mL), under Ar. ${ }^{b}$ NMR yield using 1,3,5-trimethoxybenzene as an internal standard. ${ }^{c}$ Conversion after $7 \mathrm{~h} .{ }^{d}$ Conversion after $2 \mathrm{~h} .{ }^{e}$ Conversion after $4 \mathrm{~h}$.

Fortunately, when Ru-1c or Ru-1d (0.1 mol\%) were activated by $0.1 \mathrm{~mol} \%$ of $\mathrm{AuCl}$, expected internal olefins P12 and P13 were produced in good yields and excellent purity (95->97\%) after $20 \mathrm{~min}$. of reaction. It is noteworthy that the mixed SIMes/cyclooctylıMes indenylidene complex Ru-1b led to a significant alteration of the purity for P13 (87\%), similarly to usual SIMes-based Ru-catalyst (Grubbs $2^{\text {nd }}$ generation). ${ }^{12 a}$ We surmised that the $\operatorname{SIMes}(\mathrm{Cl})_{2} \mathrm{Ru}$-methylidene versus cyclooctyllMes $(\mathrm{Cl})_{2} \mathrm{Ru}$-methylidene active species was formed in the reactive media. In order to confirm this behavior, the stoichiometric transmetalation of $\mathrm{Ru}-\mathbf{1 b}$ with $\mathrm{CuCl}$ in presence of $\mathbf{L} \mathbf{1}$ was thus attempted. As depicted in Scheme 3, SIMesHoveyda catalyst Ru-2b and the related cyclooctyllMes-CuCl complex Cu-1a were produced in respectively 95 and $75 \%$ yields, evidencing unambiguously that cyclooctylıMes acts as the labile ligand.

\section{Conclusions}

A practical protocol allowing an efficient activation of robust ruthenium olefin metathesis complexes featuring unsymmetrical unsaturated $\mathrm{u} 2-\mathrm{NHCs}$ was developed. By adding copper(I) or gold(I) chloride salts, a transmetalation process occurred to trap the labile u2-NHC ligand and to form well-defined $\mathrm{CuCl}$ - and $\mathrm{AuCl}-\mathrm{NHC}$ complexes in the reactive media. An impressive catalytic initiation rates was achieved with full-conversions reached within a few minutes, even at 30 ${ }^{\circ} \mathrm{C}$. The resulting Ru-active species demonstrated remarkable 
catalytic performances towards a range of RCM and SM transformations. Taking the opportunity that Au- or Cu-NHC complexes are cleanly formed in the media, further investigations on the development of dual catalytic reactions are currently underway in our laboratory. ${ }^{19}$

Scheme $\mathbf{2}$ Scope of metathesis transformations catalyzed by Ru-1c,1d/CuCl or AuCl ${ }^{a}$

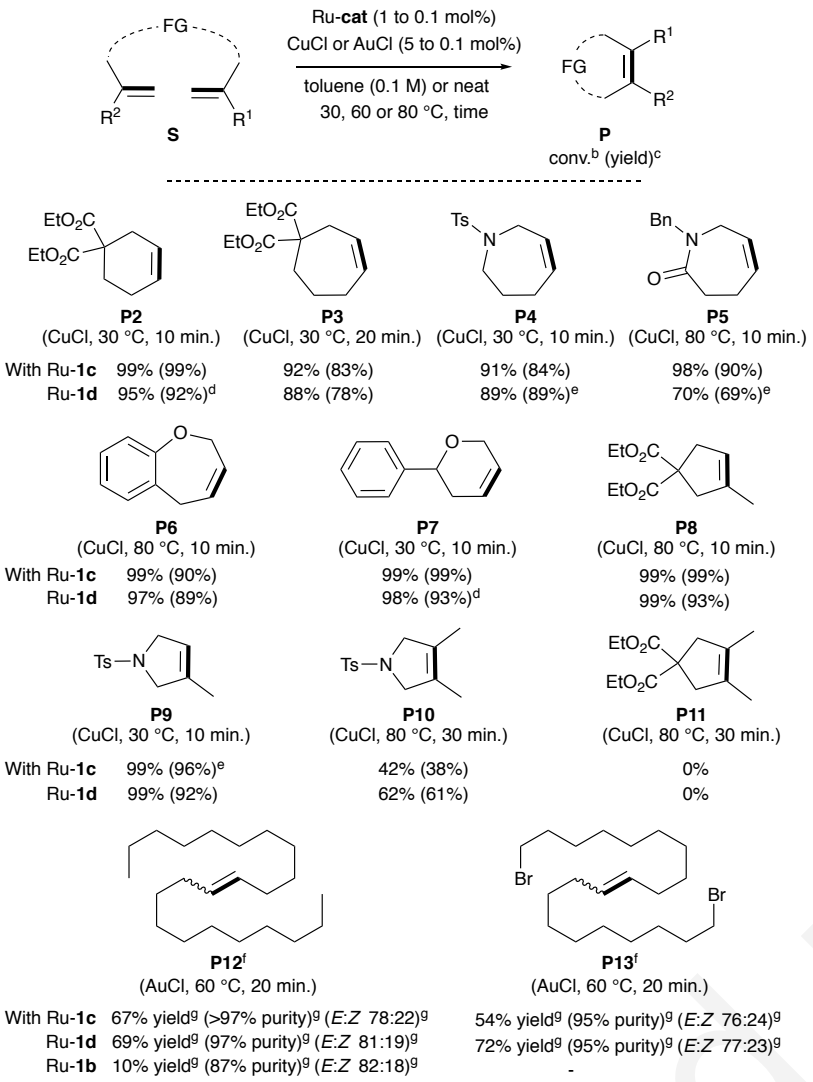

${ }^{a}$ Reaction conditions: Substrate $\mathbf{S}(1 \mathrm{mmol})$, catalyst $(0.01 \mathrm{mmol})$, activator $(0.05$ $\mathrm{mmol})$, toluene $(1 \mathrm{~mL})$, under $\mathrm{Ar} .{ }^{b}$ Determined by ${ }^{1} \mathrm{H}$ NMR spectroscopy. ${ }^{c} \mathrm{NMR}$ yield using 1,3,5-trimethoxybenzene as an internal standard. ${ }^{d} 30 \mathrm{~min}$. of reaction. ${ }^{e} 20 \mathrm{~min}$. of reaction. ${ }^{f}$ Performed in neat with $0.1 \mathrm{~mol} \%$ of catalyst and $0.1 \mathrm{~mol} \%$ of AuCl. ${ }^{g}$ Yield, purity and $E / Z$ ratio were determined by GC (see ESI for details).

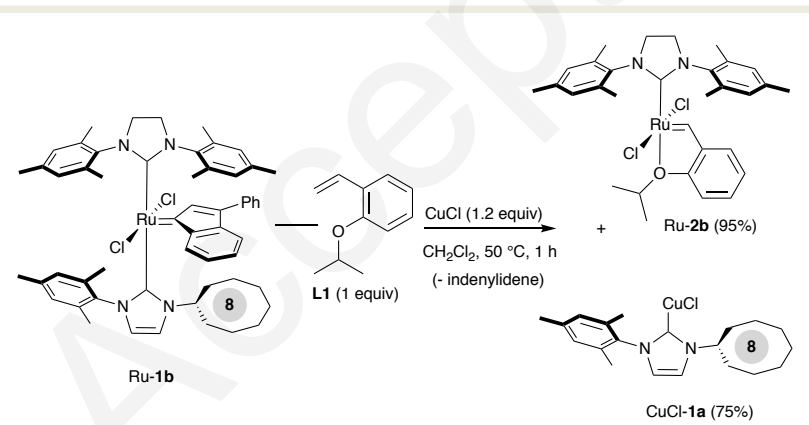

Scheme 3 Transmetalation process between $\mathrm{Cu}(\mathrm{I}) \mathrm{Cl}$ and mixed NHC Ru-1b complex

\section{Acknowledgements}

We thank the Centre National de la Recherche Scientifique (CNRS) and the Ecole Nationale Supérieure de Chimie de Rennes (ENSCR). This work was supported by the ANRT and DEMETA S.A.S. (CIFRE $n^{\circ} 2014 / 0702$ and $n^{\circ} 2017 / 0873$, grants to A.D and F.K). We are grateful to Elsa Caytan and the PRISM core facility (Biogenouest $\odot$, UMS, Biosit, Université de Rennes 1) for RMN experiences.

\section{Conflicts of interest}

The authors declare no conflict of interest

\section{Notes and references}

1 R. H. Grubbs, A. G. Wenzel, D. J. O'Leary, E. Khosravi, (Eds.) Handbook of Metathesis, $2^{\text {nd }}$ Edition; Wiley-VCH: Weinheim, Germany, 2015

2 S. T. Nguyen, L. K. Johnson, R. H. Grubbs and J. W. Ziller, J. Am. Chem. Soc. 1992, 114, 3974.

3 K. Grela (Ed.), Olefin Metathesis: Theory and Pratice, Wiley- $\mathrm{VCH}$ : Weinheim, Germany, 2014

4 M. Scholl, S. Ding, C. W. Lee and R. H. Grubbs, Org. Lett. 1999, 1, 953.

5 G. C. Vougioukalakis and R. H. Grubbs, Chem. Rev. 2010, 110, 1746.

6 T. Weskamp, W. C. Schattenmann, M. Spiegler and W. A. Herrmann, Angew. Chem. Int. Ed. 1998, 38, 2490.

7 T. Ung, A. Helj, R. H. Grubbs and Y. Schrodi, Organometallics 2004, 23, 5399.

8 For a mechanical activation, see: R. T. M. Jakobs and R. T. Sijbesma, Organometallics 2012, 31, 2476.

9 (a) T. Vorfalt, S. Leuthäusser and H. Plenio, H. Angew. Chem. Int. Ed. 2009, 48, 5191; (b) V. Sashuk, L. H. Peeck and H. Plenio, Chem. Eur. J. 2010, 16, 3983.

10 (a) X. Bantreil, R. A. M. Randall, A. M. Z. Slawin and S. P. Nolan, Organometallics 2010, 29, 3007; (b) L. H. Peeck and H. Plenio, Organometallics 2010, 29, 2761.

11 B. K. Keitz, J. Bouffard, G. Bertrand and R. H. Grubbs, J. Am. Chem. Soc. 2011, 133, 8498

12 (a) A. Dumas, S. Colombel-Rouen, I. Curbet, G. Forcher, F. Tripoteau, F. Caijo, P. Queval, M. Rouen, B. Baslé and M. Mauduit, Cat. Sci. Techn. 2019, 9, 436; for a cationic parent Ru complex, see: (b) M. Rouen, P. Queval, L. Faliven, J. Allard, L. Toupet, C. Crévisy, F. Caijo, B. Baslé, L. Cavallo and M. Mauduit, Chem. Eur. J. 2014, 20, 13716. (c) During the drafting of this manuscript, an elegant mode of activation for bis-IMes Rubenzylidene complex (Herrmann's complex) involving a photoredox catalyst was reported: C. Theunissen, M. A. Ashley and T. Rovis, J. Am. Chem. Soc. 2019, 141, 6791.

13 The molar ratio of $\mathrm{HCl}$ need to be controlled and adapted for each metathesis reaction and requires a titration before use.

14 (a) E. L. Dias, S. T. Nguyen and R. H. Grubbs, J. Am. Chem. Soc. 1997, 119, 3887; (b) M. Rivard and S. Blechert, Eur. J. Org. Chem., 2003, 2225.

15 S. B. Garber, J. S. Kingsbury, B. L. Gray and A. H. Hoveyda, J. Am. Chem. Soc. 2000, 122, 8168

16 M. D. Schulz, M. B. J. Atkinson, R. J. Elsey and M. M. Thuo, Transition Met. Chem., 2014, 39, 763.

17 (a) T. Ritter, A. Hejl, A. G. Wenzel, T. W. Funk and R. H. Grubbs, Organometallics, 2006, 25, 5740. (b) While CuCl could interact with olefins, no impact on the metathesis productivity was observed, see figures S70 and S71 in ESI.

18 For a plausible explanation, see: V. Thiel, K.-J. Wannowius, C. Wolff, C. M. Thiele and H. Plenio, Chem. Eur. J. 2013, 19, 16403.

19 G. K. Zielinski and K. Grela, Chem. Eur. J. 2016, 22, 9440. 